\title{
JURISDIÇÃO E AUSÊNCIA DE UMA TEORIA DA DECISÃO
}

[Jurisdiction and the Lack of a Decision Theory]

\author{
LENIO LUIZ STRECK* \\ Universidade do Vale do Rio dos Sinos (Unisinos), \\ São Leopoldo, Rio Grande do Sul, Brasil
}

\begin{abstract}
Resumen
Los teóricos del Derecho no han dado la debida importancia para la decisión jurídica. En las discusiones sobre la superación del positivismo jurídico, los teóricos han privilegiado la cuestión de la interpretación. Sin embargo, no es difícil percibir esa ausencia. Uno de los indicios es la institucionalización de mecanismos vinculantes en la legislación brasileña, como los precedentes vinculantes y la repercusión general, destinados a poner
\end{abstract}

\begin{abstract}
Legal scholars have not attached due importance to legal decision. In discussions on overcoming legal positivism, legal theorists have privileged the matter of interpretation. However, it is not difficult to perceive this absence. One indication of it is the Brazilian law's institutionalization of binding mechanisms, such as binding precedents and general repercussion, aimed at actually stopping that "hermeneutic state situation" that took place in
\end{abstract}

RECIBIDO el 19 de junio y ACEPTADo el 30 de noviembre de 2013

* Profesor Titular de la Universidade do Vale do Rio dos Sinos e de la Universidade Estácio de Sá. Doctor en Derecho por la Universidade Federal de Santa Catarina, postdoctorado en Derecho por la Faculdade de Direito da Universidade de Coimbra. Profesor visitante de la Universidad Javeriana, Bogotá, Colombia. Miembro Catedrático de la Academia Brasileira de Direito Constitucional, Presidente de Honor del Instituto de Hermenéutica Jurídica. Investigador de la Universidad de Deusto, Madrid, España. Dirección postal: Avenida Unisinos, 950, Cristo Rei, São Leopoldo, Rio Grande do Sul, Brasil. CEP 93.022-000, Dirección electrónica: lenio@unisinos.br 
exactamente el freno a ese "estado de naturaleza hermenéutica" que se instaló en Brasil, especialmente en los primeros años de la década 90 del siglo XX. Por lo tanto, este trabajo tiene como objetivo presentar algunos elementos críticos para una mejor comprensión del problema.

\section{Palabras Clave}

Teoría de la decisión - Positivismo jurídico - Constitucionalismo contemporáneo - Hermenéutica jurídica.
Brazil, especially during the early 1990's. Therefore, the purpose of this work is to present some critical elements to better understand the problem.

KEYWORDS

Decision Theory - Legal Positivism - Contemporaneous Constitutionalism - Legal Hermeneutics.

\section{A “QuestÃo dA deCis Ão” COMO UM PROBLEMA DE VALIDADE DO DISCURSO JURÍDICO}

A hermenêutica filosófica tem sido impropriamente criticada no campo do direito pelo fato de que, embora ela tenha oferecido o modo mais preciso de descrição do processo compreensivo, por outro lado ela não teria possibilitado a formação (normativa) de uma teoria da validade da compreensão assim obtida. Esse é um problema central que precisa ser enfrentado com muito cuidado. Trata-se de discutir as condições para a existência de uma teoria da decisão, o que implica discutir o problema da validade daquilo que se compreende e explicita na resposta. Afinal, interpretar é explicitar o compreendido, segundo Gadamer.

Validade foi, sem dúvida nenhuma, a expressão de ordem das teorias do direito surgidas na primeira metade do século XX. Através deste termo queria-se apontar para as possibilidades de determinação da verdade de uma proposição produzida no âmbito do direito. Ou seja, no contexto das teorias do direito que emergiram nesta época a preocupação estava em determinar as condições de possibilidade para a formação de uma ciência jurídica. Assim, penso que, para se pensar em uma ciência jurídica, primeiro é preciso estar de posse de um contexto de significados que nos permitam dizer a conexão interna que existe entre verdade e validade.

O positivismo de matriz kelseniana (positivismo semântico) o vínculo entre verdade e validade dava-se da seguinte maneira: a validade é atributo das normas jurídicas, enquanto prescrições objetivas da conduta; ao passo que a verdade é uma qualidade própria das proposições jurídicas que, na sistemática da Teoria Pura do Direito, descrevem - a partir de um discurso lógico - as normas jurídicas. Ou seja, novamente estamos diante da principal operação 
epistemológica operada por Kelsen que é a cisão entre Direito e Ciência Jurídica. O Direito é um conjunto sistemático de normas jurídicas validas; enquanto a Ciência Jurídica é um sistema de proposições verdadeiras ${ }^{1}$. Disso decorre o óbvio: normas jurídicas ou são válidas ou inválidas; proposições jurídicas são verdadeiras ou falsas.

A aferição da validade é feita a partir da estrutura supra-infra-ordenada (lembro aqui da metáfora da pirâmide, embora Kelsen nunca tenha se referido desta forma ao ordenamento jurídico) que dá suporte para o escalonamento das normas jurídicas. Desse modo, uma norma jurídica só será válida se puder ser subsumida a outra - de nível superior - que lhe ofereça um fundamento de validade. Assim, a sentença do juiz é valida quando pode ser subsumida a uma lei - em sentido lato - e a lei é válida porque pode ser subsumida à Constituição. Já a validade da Constituição advém da chamada norma hipotética fundamental que, por sua vez, deve ter sua validade pressuposta. Isto porque, se continuasse a regredir em uma cadeia normativa autorizativa da validade da norma aplicada, a Teoria Pura nunca conseguiria chegar a um fundamento definitivo, pois sempre haveria a possibilidade da construção de outro fundamento e isso repetido ao infinito (lembremos aqui do Trilema de Münschäusen). Assim, Kelsen oferece a tautologia como forma de rompimento com esta cadeia de fundamentação: a norma fundamental hipotética é porque é, por isso se diz que sua validade é pressuposta.

Ocorre que a relação de validade -que autoriza a aplicação da norma, fundamentando-a- não comporta uma análise lógica na qual a pergunta seria por sua verdade ou falsidade. Como afirma Kelsen²: “as normas jurídicas como prescrições, isto é, enquanto comandos, permissões, atribuições de competência, não podem ser verdadeiras nem falsas" (porque elas são válidas ou invalidas - acrescentei). Desse modo, o jusfilósofo austríaco indaga: como é que princípios lógicos como a da não contradição e as regras de concludência do raciocínio, podem ser aplicados à relação entre normas? A resposta de Kelsen ${ }^{3}$ é a seguinte: "os princípios lógicos podem ser, se não direta, indiretamente aplicados às normas jurídicas, na medida em que podem ser aplicados às proposições jurídicas que descrevem estas normas e que, por sua vez, podem ser verdadeiras ou falsas”. É dessa maneira que Kelsen liga verdade e validade, pois, no momento em que as proposições que descrevem as normas jurídicas se mostrarem contraditórias, também às normas descritas o serão e a determinação de qual proposição é a verdadeira, por consequência, determinará qual norma será igualmente válida.

${ }^{1}$ Kelsen, Hans, Teoria pura do Direito (tradução de João Baptista Machado, São Paulo, Martins Fontes, 1985), p. 78.

${ }^{2}$ Ibíd., p. 82.

${ }^{3}$ Ibíd. 
Já no chamado "positivismo moderado" de Herbert Hart algumas diferenças são notadas. No que tange ao predomínio da determinação da validade com critério absoluto para determinação de fundamento do direito, não há grandes dessemelhanças. Porém, é na forma como Hart formula o fundamento do ordenamento jurídico que as divergências entre o seu modelo teórico e aquele fornecido por Kelsen aparecem com maior evidência. Com efeito, vimos que Kelsen resolve o problema do regresso ao infinito de seu procedimento dedutivista para determinação da validade com uma tautológica norma hipotética fundamental. Ou seja, ele se mantém no nível puramente abstrato da cadeia de validade de seu sistema e resolve o problema do fundamento neste mesmo nível, a partir de uma operação lógica.

Já Hart usará outro expediente para resolver o problema do fundamento. $\mathrm{Na}$ sua descrição do ordenamento jurídico, identificará a existência de dois tipos distintos de regras (normas): as primárias e as secundárias. As chamadas regras primárias são aquelas que determinam direitos e obrigações para uma determinada comunidade política. Tais regras seriam aquelas que estabelecem o direito de propriedade, de liberdade etc. Já as regras secundárias são aquelas que autorizam a criação de regras primárias. Neste caso, uma regra que estipule como deverão ser feitos os testamentos, é um exemplo de uma regra secundária e todas as regras que criem órgãos, estabeleçam competências ou fixem determinados conteúdos que deverão ser regulados concretamente pelas autoridades jurídicas também são consideradas regras secundárias. Portanto, o que determina a validade do direito em $\mathrm{Hart}^{4}$ é a compatibilização -dedutivista, evidentemente- das regras que determinam obrigações (primárias) com as regras secundárias. Hart afirma ainda que, em sociedades menos complexas -sendo que por sociedades menos complexas devem ser entendidas todas aquelas que antecedem a modernidade-, não existiam regras secundárias desenvolvidas com a sofisticação que encontramos em nosso contexto atual. Neste caso, estas sociedades primitivas baseavam suas regras de obrigação apenas em critérios de aceitação. Como afirma Dworkin': "uma prática contém a aceitação (grifei) de uma regra somente quando os que seguem essa prática reconhecem a regra como sendo obrigatória e como uma razão para criticar o comportamento daqueles que não a obedecem". Nos modernos sistemas jurídicos, toda fundamentação do direito depende da articulação do conceito de validade. No entanto, há uma única regra -que Dworkin chama de "regra secundária fundamental"- que rompe com a necessidade de demonstração da validade e se baseia em critérios de

${ }^{4}$ Hart, Herbert, $O$ conceito de Direito (tradução de A. Ribeiro Mendes. 3 a edição, Lisboa, Calouste Gulbenkian, 1996), p. 89

${ }^{5}$ Dworkin, Ronald, Levando os direitos a Sério (tradução de Nelson Boeira, São Paulo, Martins Fontes, 2002), p. 32. 
aceitação para determinação de seu fundamento: trata-se da chamada regra de reconhecimento. Em síntese: a regra de reconhecimento está para Hart assim como a norma hipotética fundamental está para Kelsen: em ambos os casos funcionam como resposta para o problema do fundamento último do sistema jurídico. Todavia, a regra de reconhecimento tem um caráter mais "sociológico" do que a norma hipotética fundamental kelseniana. Como afirma Hart ${ }^{6}$ : "sua existência (da regra de reconhecimento - acrescentei) é uma questão de facto".

Mas o que há de errado com os projetos positivistas de ciência jurídica? Veja-se que a discussão aqui posta diz respeito às tentativas de superação do positivismo exegético ocorridas no século $\mathrm{XX}$, isto é, quando a razão, colocada plenipotenciariamente no plano da lei, tinha a função de abranger, de forma antecipada, todas as hipóteses de aplicação. Isto é, as tentativas de superação do exegetismo (nas suas três vertentes - francesa alemã e inglesa) acabaram reféns da vontade (de poder!), o que pode ser visto, por exemplo, desde a jurisprudência dos interesses até a jurisprudência dos valores, passando pelo pessimismo moral do oitavo capítulo da Teoria pura do Direito, pelo positivismo fático de Alf Ross e Olivecrona (posturas realistas) e pelo positivismo discricionarista de Hart.

O que há em comum nas teses surgidas na aurora do século XX até as teses forjadas no final do século? A resposta não é difícil: o voluntarismo, mascarado na aposta discricionário-positivista e no decisionismo, formas mais ou menos acabadas de protagonismo judicial (que, como se sabe, não fizeram vítimas apenas no direito constitucional ou na teoria do direito, mas, sim, no processo civil, por intermédio do instrumentalismo, e no processo penal, via inquisitivismo).

Nesse contexto também se inserem, mais proximamente, as teses do positivismo inclusivo de Robert Alexy, que, ao apostar na construção de regra da ponderação para a solução dos "hard cases", não abre mão do protagonismo representado pelo solipsismo judicial, que se manifesta pelo poder discricionário. Nesse sentido, é possível dizer que há um sério problema com esse conceito de ciência, como diria Heidegger, porque esconde um modo mais originário do fenômeno da verdade. Isso porque a verdade deve ser percebida já em meio à lida com o mundo prático e não reduzida ao universo teorético das ciências. Afinal, a própria verdade "teórica" das ciências é produto da interpretação projetada pela compreensão.

Portanto, há algo anterior à verdade da ciência que, de certa forma, lhe é condição de possibilidade. No caso do direito, o equivoco dos projetos positivistas está no próprio recorte na totalidade do ente que tais teorias

${ }^{6}$ Hart, Herbert, O conceito de Direito, cit. (n. 5), p. 121. 
efetuam para caracterizar o estudo do fenômeno jurídico. Dito de outro modo, o modelo excessivamente teórico de abordagem gera uma espécie de asfixia da realidade, do mundo prático. Ou seja, o contexto prático das relaçôes humanas concretas, de onde brota o direito, não aparece no campo de análise das teorias positivistas. Isso gera problema de diversos matizes. $\mathrm{O}$ fato de nenhuma das duas teorias conseguir resolver o problema da eficácia do sistema pode ser elencado com um destes problemas.

Assim, o principal problema aparece quando se procura determinar como ocorre e dentro de quais limites deve ocorrer à decisão judicial. Ambas as teorias apostam na vontade do intérprete para resolver o problema gerando a discricionariedade judicial. Ora, evidente que tais teorias sofrem de um letal déficit democrático. É de se perguntar: como justificar, legitimamente, uma decisão tomada pelo poder judiciário? Isso tais teorias não respondem. E nem poderiam responder, uma vez que essa dimensão dos acontecimentos fica fora de seu campo de análises.

Dizendo de outro modo, essa problemática da "validade da explicitação da compreensão" (portanto, da validade da interpretação) deve ser analisada a partir da destruição do método que é proporcionada por Gadamer. Com efeito, não há nisso um déficit de metodologia ou de racionalidade. Essa ruptura não significou um ingresso na irracionalidade ou no relativismo filosófico. Muito pelo contrário. Assim como a integridade em Dworkin, a hermenêutica está fundada na autoridade da tradição, que pode ser autêntica e inautêntica, além da importância do texto (que, em Gadamer, é um evento, como demonstrado em Verdade e consenso). Gadamer deixa claro que a ausência do método não significa que se possa atribuir sentidos arbitrários aos textos. Na medida em que a interpretação sempre se dá em um caso concreto, não apenas fica nítida a impossibilidade de cisão entre quaestio facti e quaestio iuris. A hermenêutica não trata apenas da faticidade; ela não apenas explica como se dá o sentido ou as condições pelas quais compreendemos. $\mathrm{Na}$ verdade, por ela estar calcada na circularidade hermenêutica, fato e direito se conjuminam em uma síntese, que somente ocorre concretamente, na applicatio (lembremos sempre que não se cinde conhecimento, interpretação e aplicação). Se interpretar é explicitar o que compreendemos, a pergunta que se faz é: essa explicitação seria o locus da validade? Se verdadeira essa assertiva, então estaríamos diante de outro problema: o que fazer com a quaestio facti?

\section{Pode-Se FAlar DE UMA TEORIA DA VAlidAdE NA HeRMENÊUTICA} FILOSÓFICA E NA TEORIA INTEGRATIVA DWORKINIANA?

Não é desarrazoado afirmar que a hermenêutica filosófica e a teoria integrativa dworkiniana tratam de uma teoria da decisão. A diferença é 
que ambas não admitem aquilo que está no cerne da expressiva maioria das teorias jurídicas contemporâneas: a discricionariedade dos juízes. Claro que Dworkin é explícito nesse sentido, o que pode ser visto no seu debate com Hart. Já a hermenêutica filosófica tem esse caráter antidiscricionario a partir de seu antirrelativismo. Essa problemática passa pela discussão da relação entre semântica e hermenêutica.

Com efeito, em Verdade e método II, Gadamer escreve um texto que aborda precisamente os fatores determinantes das principais diferenças entre essas duas correntes que, segundo ele, são as únicas que podem reivindicar para si a pretensão de universalidade própria da filosofia uma vez que ambas se ocupam do problema da linguagem e ambas partem da constatação de que a configuração da expressão de nosso pensamento é linguística. Nos termos de Gadamer?: "a semântica parece descrever o campo dos dados de linguagem ("Gegebenheitsfeld”), observando-os desde fora, de tal modo que é possível desenvolver uma classificação dos modos de comportamento no trato com os signos [...]. Por outro lado, a hermenêutica ocupa-se com o aspecto interno no uso do universo semântico, ou melhor, com o processo interno de fala, que visto de fora, apresenta-se como a utilização de um universo de signos"

Isso significa, basicamente, duas coisas: primeiro a semântica se movimento em uma dimensão que concebe um uso instrumental da linguagem. Assim, o pluralismo de significados deve ser corrigido por um "treinamento" da mente que lida com os fenômenos linguísticos a partir da antecipação das diversas possibilidades de contextos de uso. Já a hermenêutica entende que esse uso instrumental da linguagem é impossível. Muito mais do que carregar a linguagem conosco é ela, a linguagem, que nos carrega. $\mathrm{O}$ ato de fala não é dominado pelo falante; ele envolve um fluxo contínuo no qual o falante encontra-se, desde sempre, imerso. Por outro lado, o problema central da semântica começa com o signo e sua projeção no campo de objetos (mundo). Para a hermenêutica a questão é anterior aos signos ou enunciados. Não é apenas o dito que importa, mas, muito mais, o não dito. Vale dizer, essa "dimensão interna de fala" produz um campo de motivação para os enunciados que, simplesmente, não aparece na superfície do discurso. Esse campo de motivação se produz a partir da imersão num certo contexto de facticidade e historicidade do intérprete. Basicamente, essa dimensão do não dito é que pode gerar os maiores problemas hermenêuticos com relação a controvérsias interpretativas sobre os enunciados. A descoberta dessa dimensão fundante do enunciado se dá a partir de uma lógica de perguntas e respostas. A per-

${ }^{7}$ Gadamer, Hans-Georg, Verdade e método. Traços fundamentais de uma hermenêutica filosófica (Tradução de Flávio Paulo Meurer, $3^{\text {a }}$ edição, Petrópolis, Vozes, 1999), p. 205. 
gunta procura descobrir o sentido da motivação que impulsiona o texto. A resposta se confirma na medida em que ela se ajusta ao objeto interpretado.

De todo modo, atentando-se para a dimensão do não dito, a hermenêutica vai além da semântica, posicionando o foco do problema numa dimensão mais concreta de análise. Vale dizer, o discurso judicial apresenta a resposta para o caso. Juízos de prognose ou sobre as consequências advindas da decisão (o vulgo consequencialismo) não estão em jogo em uma análise à luz da hermenêutica. O direito deve dar uma resposta para "o" caso apresentado. Sua aplicação aos casos similares posteriores deverá ser discutida, de novo, segundo as especificidades de cada um e sobre o que poderia ser retirado como "holding" do julgamento anterior. A prognose é uma atividade própria do legislador. Na verdade, é possível dizer que a prognose é algo que atina, particularmente, à estrutura dos argumentos de política: procura apresentar projetos que se destinam a conquistar maior bem-estar coletivo ou uma melhora nas condições socioeconômicas.

Já a decisão judicial somente se sustenta por argumentos de princípios. Essa estrutura principiológica que se manifesta no momento decisório só pode ser explicitada através de um esforço reflexivo que é hermenêutico. Ora, os princípios não aparecem na superfície do discurso; não são da ordem do apofântico (mostrativo), mas, sim, do hermenêutico (condição de possibilidade, estruturante). Sendo mais claro, a dimensão do hermenêutico é aquela de onde emanam os motivos da enunciação.

Essa característica da hermenêutica deve sempre ser ressaltada quando se fala em Teoria da Decisão porque ela demonstra, de maneira privilegiada, o caráter não relativista desse paradigma filosófico. Nesse particular, a admoestação heideggeriana de que o enunciado não é o lugar da verdade; mas a verdade é que é o lugar do enunciado. Ou seja, o juízo veritativo é “motivado" por uma dimensão de profundidade da enunciação.

Evidentemente, esse tipo de verdade não é produzido nem por uma subjetividade assujeitadora, nem por uma sujeição do intelecto à essência dos objetos. Conforme bem diz Stein ${ }^{8}$ : "portanto, nem subjetivista, nem objetivista, mas sim, uma fundamentação de caráter diferente, é uma fundamentação de caráter prévio, de caráter a priori. É uma fundamentação em que já sempre existe um compreendemos a nós mesmos. Isso é uma antecipação prévia de sentido que se explica na compreensão do ser".

De tudo o que foi dito, fica claro que se a hermenêutica e a teoria integrativa não se preocupassem com a decisão, estas seriam relativistas, admitindo várias respostas para cada problema jurídico. Não há dúvida de que uma

${ }^{8}$ STEIn, Ernildo, Diferença e Metafísica: Ensaio sobre a desconstrução (Porto Alegre, Edipucrs, 2000), p. 58. 
teoria jurídica democrática deve se preocupar com a validade normativo-jurídica do concreto juízo decisório. $\mathrm{O}$ que não se pode concordar é que, para alcançar esse juízo decisório são possíveis juízos discricionários, o que reforça(ria) novamente o solipsismo interpretativo. Numa palavra: a questão da validade reside na circunstância de que não podemos simplesmente confundir essa validade com uma espécie de imposição ontológica (no sentido clássico) nas questões com que se ocupam determinados campos do conhecimento cientifico. Também não podemos mais pensar a validade como uma cadeia causal sucessiva que tornaria verdadeiro um determinado conjunto de proposições jurídicas. A validade é o resultado de determinados processos de argumentação em que se confrontam razões e se reconhece a autoridade de um argumento.

E que fique bem claro que o reconhecimento da autoridade de um argumento não está ligado a uma imposição arbitrária. Pelo contrário, a hermenêutica é incompatível com qualquer tipo de arbitrariedade. Como afirma Gadamer", ao proceder a reabilitação da autoridade da tradição: "o reconhecimento da autoridade está sempre ligado à idéia de que o que a autoridade diz não é uma arbitrariedade irracional, mas algo que pode ser inspecionado principalmente. É nisso que consiste a essência da autoridade que exige o educador, o superior, o especialista". Em conseqüência, devemos primeiro compreender o problema da validade como uma questão que pode ser amplamente desenvolvida pela ciência e pela lógica. Mas não há duvida de que aqui também reaparece certo tipo de pressuposto que está sempre presente para produzir o campo comum de interação próprio para troca de argumentos.

Mas, penso que também poderíamos discutir o problema da validade em outro nível. Sob esse aspecto, a validade foi durante o neokantismo muitas vezes apresentada como o sentido que sustenta qualquer teoria dos enunciados. É desse conceito de validade que Heidegger extrai a necessidade de se fazer uma distinção entre a validade na ciência e a validade na filosofia, questão que ele, sob certos aspectos, utilizou para se inspirar na lenta determinação do que significa a diferença ontológica, na medida em que a validade que se coloca no nível dos entes é a validade para a qual nós temos instrumentos de argumentação/discussão, enquanto a outra validade termina já sempre operando nesses tipos de argumentação, que é o sentido. E esse sentido dos neokantianos passou em Heidegger precipuamente no conceito de ser. Por isso, para alguns autores, a diferença ontológica nasceu de uma leitura que Heidegger fez de certas discussões neokantianas ${ }^{10}$.

\footnotetext{
${ }^{9}$ Gadamer, H.-G., Verdade e método, cit. (n. 8), p. 420.

${ }^{10}$ Também STEIN, Ernildo, Uma breve introdução à Filosofia (2a edição, Ijuí, Uni-
} 
É preciso entender que a hermenêutica (filosófica) -e Dworkin segue essa mesma reflexão- (re)valoriza a dimensão prática da retórica oferecendo a possibilidade de instauração de um ambiente no qual os problemas da realidade são resolvidos concretamente, no interior desta mesma realidade, e não numa instância superior, de cunho ideal que, posteriormente, passa a ser aplicada por mimetismo à realidade. Note-se, por exemplo, que as críticas de que existe um excesso de abstração na teoria de Dworkin apresentam um equívoco de base: a orientação filosófica de Dworkin vai em direção a uma análise pragmática da realidade. Tal acusação poderia ser feita às teorias argumentativas e epistemo-procedurais, mas não à Dworkin ou à hermenêutica filosófica.

Em defesa de Dworkin -circunstância que pode ser estendida à hermenêutica filosófica- é preciso lembrar que, enquanto um procedimentalista como Habermas desonera os juízes da elaboração dos discursos de fundamentação - porque desacredita na possibilidade de os juízes poderem se livrar da razão prática (eivada de solipsismo) - ele (Dworkin) ataca esse problema a partir da responsabilidade política de cada juiz/intérprete/ aplicador, obrigando-o ("has a duty to") a obedecer a integridade do direito, evitando que as decisões se baseiem em raciocínios ad hoc (teleológicos, morais ou de política).

Insista-se: quando Dworkin diz que o juiz deve decidir lançando mão de argumentos de princípio e não de políticas, não é porque esses princípios sejam ou estejam elaborados previamente, à disposição da "comunidade jurídica" como enunciados assertóricos ou categorias (significantes primordiais-fundantes). $\mathrm{Na}$ verdade, quando sustenta essa necessidade, apenas aponta para os limites que devem haver no ato de aplicação judicial (por isso, ao direito não importa as convicções pessoais/morais do juiz acerca da política, sociedade, esportes, etc; ele deve decidir por princípios). É preciso compreender que essa "blindagem" contra discricionarismos é uma defesa candente da democracia, uma vez que Dworkin está firmemente convencido e acertadamente- que não tem sentido, em um Estado Democrático, que os juízes tenham discricionariedade para decidir os "casos difíceis".

Mas isso é assim -filosoficamente- porque Dworkin compreendeu devidamente o problema do esquema sujeito-objeto, questão que, entretanto, não está devidamente esclarecida e compreendida pela teoria do direito. Exatamente por superar o esquema sujeito-objeto é que Dworkin

juí, 2005), aponta para este fato indicado no texto: “a diferença ontológica, cuja envergadura se desdobrou muito com o labor do filósofo, lhe foi ao menos possibilitada pelas análises de Emil Lask. O pensamento de Heidegger que se quer nos antípodas do problema gnosiológico, contudo, lhe deve algo de essencial" (STEIN, Ernildo, Uma breve introdução, cit. ibi). 
não transforma o seu "juiz Hércules” em um juiz solipsista e tampouco em alguém preocupado apenas em elaborar discursos prévios, despreocupados com a aplicação (decisão). Hércules é uma metáfora, demonstrando as possibilidades de se controlar o sujeito da relação de objeto, isto é, com Hércules se quer dizer que não é necessário, para superar o sujeito solipsista da modernidade, substituí-lo por um sistema ou por uma estrutura (v.g., como fazem Luhmann e Habermas). Insista-se: a teoria dworkiniana, assim como a hermenêutica, por serem teorias preocupadas fundamentalmente com a applicatio, não desoneram o aplicador (juiz) dos "Begründungsdiskurs" (discursos de fundamentação). E isso faz a diferença.

\section{RESPOSTAS A ALGUMAS CRÍTICAS À HERMENÊUTICA. O PROBLEMA DA MÁ COMPREENSÃO DO SENTIDO DE “PRÉ- COMPREENSÃO" ("VORVERSTÄNDNIS")}

A discussão sobre a decisão é atravessada, necessariamente, pelas condições de possibilidade da preservação da democracia a partir dos parâmetros do Estado Democrático de Direito. Com efeito, não teria sentido que, nesta quadra da história, depois da superação dos autoritarismos/totalitarismos surgidos no século XX e no momento em que alcançamos esse (elevado) patamar de discussão democrática do direito, viéssemos a "depender" da discricionariedade dos juízes na discussão dos assim denominados "casos difíceis" ou em face das (inexoráveis) incertezas da linguagem. Ora, pensar assim seria substituir a democracia pela "vontade do poder" (entendido como o último princípio epocal da modernidade) dos juízes ou de uma doutrina que, seguida pelos juízes, substituísse a produção democrática do direito. Essa produção democrática do direito - plus normativo/qualitativo que caracteriza o Estado Democrático de Direito- é um salto para além do paradigma subjetivista.

É nesse sentido que, ao ser antirrelativista, a hermenêutica funciona como uma blindagem contra interpretações arbitrárias e discricionariedades e/ou decisionismos por parte dos juízes. Nesse sentido, é importante esclarecer alguns pontos. Por vezes, a hermenêutica filosófica é acusada de ser irracionalista ${ }^{11}$. Diz-se que, por estar assentada na pré-compreensão, em uma sociedade plural e fragmentada como a brasileira, coexistiriam múltiplas visões de mundo ocupando esse espaço ${ }^{12}$.

${ }^{11}$ SARmento, Daniel, Interpretação constitucional, pré-compreensão e capacidades institucionais do intérprete, in Pereira De Souza Neto, Claudio - Binembojn, Gustavo (org.), Vinte anos da Constituição Federal de 1988 (Rio de Janeiro, Lumen Juris, 2009), p. 321.

${ }^{12}$ Ibíd., p. 311. 
Em defesa da hermenêutica, é preciso dizer, antes de tudo, que esta não pode ser "regionalizada", como, por exemplo, "hermenêutica constitucional" ou "hermenêutica a ser feita em países com 'múltiplas visões de mundo disputando espaço"' [ sic]. Hermenêutica é filosofia; consequentemente, não há modos diferentes de interpretar, por exemplo, o direito penal, o direito civil, o direito constitucional, o cotidiano, a mídia, etc. Esse é o caráter de universalização da hermenêutica e não de regionalização (se assim se quiser dizer).

Que fique bem claro: não se pode confundir pré-compreensão com visão de mundo, preconceitos ou qualquer outro termo que revele uma abertura para o relativismo. A pré-compreensão demonstra exatamente que não há espaço para este tipo de relativização subjetivista que acabaria, no fundo, caindo nas armadilhas de um ceticismo filosófico.

De todo modo, o que transparece das críticas é exatamente a confusão entre pré-compreensão e preconceitos. Ora, como se sabe, a pré-compreensão é do nível do a priori, antecipador de sentido. A pré-compreensão é uma espécie de totalidade que não pode ser fatiada (como se existisse uma pré-compreensão religiosa e outra leiga/laica). Não nos perguntamos por que compreendemos, pela simples razão de que já compreendemos - lembrando aquilo que ensina Heidegger: em todo discurso, enquanto um existencial do ser-aí, já há uma compreensibilidade sendo articulada. É por isso que Gadamer diz que o método chega tarde. A pré-compreensão não significa uma estrutura de caráter histórico e cultural que carateriza uma posição que se prende a um conteúdo determinado que possa ser apresentado como válido contra outro conteúdo. $\mathrm{O}$ que está em questão aqui é o problema do preconceito, que pode aparecer na ideologia, na visão de mundo e nos conflitos de caráter histórico ${ }^{13}$. Daí a lição de Heidegger (do qual -frise-se uma vez mais- se originou a hermenêutica filosófica de Gadamer) acerca da estrutura da compreensão: embora possa ser tolerado, o círculo hermenêutico não deve ser rebaixado/degradado a círculo vicioso. Ele esconde uma possibilidade positiva do conhecimento mais originário, que, evidentemente, somente será compreendida de modo adequado quando ficar claro que a tarefa primordial, constante e definitiva da interpretação continua sendo não permitir que a posição prévia (Vorhabe), a visão prévia ("Vorsicht")

${ }^{13}$ Para evitar esse tipo de mal-entendido, nada melhor do que lembrar o próprio GAdAmer, H.-G., Verdade e método, cit. (n. 8), para quem os preconceitos e opiniões prévias (e fica claro que é disso que Sarmento está falando e não da "Vorvertändnis") que ocupam a consciência do intérprete não se encontram à sua livre disposição. Por isso o intérprete não está em condições de distinguir por si mesmo e de antemão os preconceitos produtivos, que tornam possível a compreensão, daqueles outros (aqui está o ponto fulcral da confusão entre pré-compreensão e preconceitos) que a obstaculizam eque levam a equívocos. 
e a concepção prévia ("Vorbegriff") lhe sejam impostas por intuições ou noções populares (do senso comum) ${ }^{14}$. É a esses preconceitos que, por certo, o crítico Daniel Sarmento se refere. Por isso seu alvo é equivocado. Atira nos preconceitos buscando atingir a pré-compreensão (reitero que sempre estou falando a partir da pré-compreensão hermenêutico-filosófica e que é o objetivo da crítica de Sarmento). Isso não quer dizer que qualquer tipo de pensamento possa se apresentar como depurado dos elementos ideológicosvalorativos. Para diminuí-los (controlá-los) podemos apresentar justamente, por exemplo, a ideia de uma crítica das ideologias, dos valores, etc. ${ }^{15}$. É por intermédio dessa crítica que se pretendem romper certas barreiras para o diálogo e discussões. Numa palavra: Sarmento talvez tenha sido traído pelos preconceitos e não pela pré-compreensão.

Esse é o significado da pré-compreensão. Ela não é uma criação da hermenêutica filosófica de Gadamer. Ao contrário, o próprio Gadamer admite em Verdade e método que a pré-compreensão -tese fundamental para construção de sua filosofia- é uma descoberta heideggeriana. E é em Heidegger que está o mais eficaz remédio contra o relativismo. Afinal, Ser e tempo é um livro antirelativista. Numa época de pessimismos (social, econômico e filosófico), em que não faltavam teses que interpretavam o mundo no sentido do juízo final e do recomeço radical-lembro aqui de $A$ queda do Ocidente de Oswald Spengler-, Ser e tempo postula a verdade como dimensão em que o ser-aí ("Dasein") desde sempre se movimenta. Nessa medida, a questão da significância, da estrutura prévia do enunciado e da constituição existencial (prévia) da compreensão são as questões nucleares para a correta introdução ao problema da pré-compreensão e sua relação com a verdade.

${ }^{14}$ Como bem assinala Gadamer, H.-G., Verdade e método, cit. (n. 8), o que Heidegger diz aqui não é em primeiro lugar uma exigência à práxis da compreensão, mas descreve a forma de realização da própria interpretação compreensiva. A reflexão hermenêutica de Heidegger tem o seu ponto alto não no fato de demonstrar que aqui prejaz um círculo, mas que este círculo tem um sentido ontológico positivo. A descrição como tal será evidente para qualquer intérprete que saiba o que faz. Toda interpretação correta tem que proteger-se da arbitrariedade de intuiçóes repentinas, enfim, dos preconceitos e voltar seu olhar para as "coisas elas mesmas" (veja-se que textos sempre tratam de coisas, sendo que, por isso, texto é sempre um evento). Por isso, diz Gadamer, a compreensão somente alcança sua verdadeira possibilidade quando as opiniões prévias com as quais inicia não forem arbitrárias.

${ }^{15}$ Sarmento não se dá conta de que, para Gadamer, a antecipação de sentido, que guia a nossa compreensão, não é um ato da subjetividade, já que se determina a partir da comunhão que nos une com a tradição. Esse equívoco decorre do lugar de onde fala o meu crítico: o esquema sujeito-objeto. 


\section{A MESMA CRÍTICA À HERMENÊUTICA, AgORA SOB OUTRA PERSPECTIVA}

O tema é, pois, recorrente, valendo lembrar que essa crítica à falta/ ausência de racionalidade é feita também por Inocêncio Mártires Coelho, que, entretanto, confunde a hermenêutica filosófica com o "método hermenêutico-concretizador" (faz uma crítica a este, mas atinge àquela -e por isso merece ser discutida). Inicia dizendo que esse "método hermenêuticoconcretizador" é pouco diferente do método tópico-problemático (o que, por si, já constitui um problema, embora sem maior relevância para os objetivos da presente anotação). Mais ainda, assinala que os adeptos do método hermenêutico-concretizador "procuram ancorar a interpretação no próprio texto constitucional - como limite da concretização -, mas sem perder de vista a realidade que intenta regular e que, afinal, lhe esclarece o sentido; noutras palavras, trata-se de uma postura que encontra apoio, dentre outras, nas seguintes descobertas hermenêuticas de Gadamer: interpretar sempre foi, também, aplicar; aplicar o direito significa pensar, conjuntamente, o caso e a lei, de tal maneira que o direito propriamente dito se concretize; e, afinal, o sentido de algo geral, de uma norma, por exemplo, só pode ser justificado e determinado, realmente na concretização e através dela".

Na seqüência -pressupondo como fato consumado a "origem comum" do método hermenêutico-concretizador e da hermenêutica filosófica- Mártires Coelho investe contra a categoria da pré-compreensão, verbis: "Considerando, entretanto, que toda pré-compreensão, em certa medida, possui algo de irracional, pode-se dizer que, apesar dos seus esforços, os que propugnam por esse método [sic], assim como os defensores do processo tópico-problemático, ficam a dever aos seus críticos algum critério de verdade que lhes avalize as interpretações, de nada valendo, para quitar essa dívida, apelarem para uma imprecisa e mal definida verdade hermenêutica, que pode ser muito atraente como idéia, mas pouco nos diz sobre os alicerces dessa construção" ${ }^{16}$.

Coloquemos, então, as discordâncias com o autor: em primeiro lugar, o método hermenêutico-concretizador é trazido por Canotilho ${ }^{17}$ a partir de duas fontes: Hesse e Müller, não fazendo nenhuma referência a Gadamer. De fato, há em Müller (que é associado ao método estruturante) uma base gadameriana. A questão, no entanto, não é a influência de Gadamer em Müller ou Hesse, mas o modo como Gadamer é lido pelos juristas. Müller, por exemplo, usa Gadamer para justificar a relação da interpretação com a

${ }^{16}$ MÁrtires Coelho, Inocêncio, Interpretação constitucional (Porto Alegre, Fabris, 1992), p. 103.

${ }^{17}$ Canotilno, J. J. Gomes, Direito constitucional e teoria da Constituição (7a edição, Coimbra, Almedina, 2003). 
aplicação e, ao mesmo tempo, procura oferecer uma estrutura metodológica para controlar a interpretação. Não podemos esquecer da relação do pensamento de Gadamer com os métodos constitutivos da compreensão! Em Gadamer, não é possível associar métodos e a antecipação da compreensão na circularidade hermenêutica. Isso de modo algum! Na seqüência, tal como já fizera Daniel Sarmento, Mártires Coelho confunde pré-compreensão com preconceitos, ou seja, utiliza pré-compreensão como se fosse preconceito, ideologia, subjetividades ou visão de mundo. Realiza, portanto, um processo de "fatiamento" da pré-compreensão.

Insisto: a pré-compreensão é uma espécie de todo que sempre nos antecipa quando nos relacionamos com os entes no mundo. Em hipótese alguma isso representa uma ideia, mas pelo contrário isso é possibilitado por um ver fenomenológico que acessou o mundo prático em suas estruturas mais originárias. Isso implica a seguinte pergunta: por que a pré-compreensão de que fala Gadamer -que, insista-se, é estruturante, que antecipa o sentido (novamente a razão hermenêutica de que fala Schnädelbach) - seria irracional? Por que a hermenêutica não oferece nenhum critério "garantidor" da verdade? Novamente, o que está em jogo é uma idéia de que o racional só é alcançado quando se tem um método disponível para assegurar a organização e o processamento do processo de conhecimento do direito.

Mas, observemos: o ataque de Mártires Coelho não é -diretamente- à hermenêutica filosófica. Mas tudo indica que a confusão entre hermenêutica e método concretizador acabou por propiciar uma cobrança de "racionalidade" da hermenêutica, uma vez que o professor brasiliense diz de nada valer, "para quitar essa dívida, apelarem para uma imprecisa e mal definida verdade hermenêutica". Aqui transparece, nitidamente, que o lugar da crítica de Mártires Coelho não é o "ontological turn" e, sim, o da filosofia da consciência, enfim, do lugar da fala do método tradicional da modernidade. Gadamer, como tenho insistido, faz uma ruptura com o método a partir da superação do esquema sujeito-objeto, confrontando-se, abertamente, com o sujeito solipsista ("Selbstsüchtiger") da modernidade. Mas, confundir essa ruptura com o método com a instauração de uma irracionalidade (ou um livre atribuir de sentidos) é confundir, também neste ponto, os níveis em que se dão a compreensão e a explicitação dessa compreensão.

Ora, Mártires Coelho cobra da hermenêutica uma razão instrumental que a hermenêutica afastou justamente em face do esquema sujeito-objeto. Mas é preciso compreender que, no lugar disso, Gadamer coloca a autoridade da tradição, a aferição da verdade hermenêutica a partir dos pré-juízos legítimos e ilegítimos, circunstância que reforça a relação da hermenêutica para com o direito, mormente pelo locus privilegiado representado pela Constituição. Não esqueçamos -novamente- da applicatio gadameriana 
e sua incindibilidade para com a interpretação. Essa circunstância favorece em Dworkin a utilização da integridade e da coerência como modos de controlar/amarrar o intérprete, evitando discricionariedades e arbitrariedades, problemática que perpassa toda a presente obra. E, não esqueçamos, numa palavra, o que Gadamer dizia acerca da acusação de irracionalidade e/ou de relativismo à hermenêutica: o relativismo não deve ser combatido; deve ser destruído. Parece claro isso: o irracionalismo é, paradoxalmente, produto da "racionalidade instrumental" da modernidade!

Por fim, importa referir que essas críticas de Mártires Coelho tornam-se problemáticas porque se originam de um território ocupado pelo proceduralismo das teorias argumentativas. Ainda, numa palavra: com Habermas e Luhmann podemos, ao menos, discutir uma alternativa para o pensamento pós-metafísico (Habermas) e, até mesmo, as possibilidades de qualquer uma dessas alternativas (Luhmann). Lembremos que Habermas é anti-relativista, anti-discricionarista, assim como Dworkin. Com certeza, Luhmann não compactua com irracionalidades (pode-se dizer que, nele, as contingências são evitadas pelas estruturas). O que não é possível é avaliar o pensamento hermenêutico-gadameriano-dworkiniano pela lente da filosofia da consciência (portanto, pela metafísica moderna).

Por tudo isso, discutir as condições de possibilidade da decisão jurídica é, antes de tudo, uma questão de democracia. Por isso, deveria ser despiciendo acentuar ou lembrar que a crítica à discricionariedade judicial não é uma “proibição de interpretar”. Ora, interpretar é dar sentido ("Sinngebung”). É fundir horizontes. E direito é um sistema de regras e princípios, "comandado" por uma Constituição. Assim, afirmar que as palavras da lei (lato sensu) contêm vaguezas e ambigüidades e que os princípios podem ser - e na maior parte das vezes são - mais “abertos" em termos de possibilidades de significado, não constitui novidade.

O que deve ser entendido é que a realização/concretização desses textos (isto é, a sua transformação em normas) não depende de uma subjetividade assujeitadora (esquema sujeito-objeto), como se os sentidos a serem atribuídos fossem fruto da vontade do intérprete, dando assim razão a Kelsen, para quem "a interpretação a ser feita pelos juízos é um ato de vontade" [sic]. Isso para dizer o mínimo!

Nessa mesma linha é possível dizer que também Eduardo Appio não entendeu a tese que proponho para combater o problema da discricionariedade no direito. Com efeito, em trabalho recente o autor apresenta críticas a pontos específicos de minha obra, catalogando-a -em título específico de seu texto-sob o rótulo de "interpretativismo hermenêutico de Lenio Streck"18.

${ }^{18}$ Appıo, Eduardo, Direitos das minorias (São Paulo, Revista dos Tribunais, 2009), 
De plano, um problema se apresenta. Parece claro que há uma articulação equivocada do conceito de interpretativismo. Como é cediço, interpretativistas são as posturas teóricas que defendem uma interpretação originalista da Constituição. Na medida em que tais teorias surgem nos Estados Unidos, trata-se de um originizalismo com relação à Constituição Norte-americana. Sendo mais claro, há uma disputa histórica entre os teóricos norte-americanos - pelo menos desde o clássico artigo de Thomas Grey que, pela primeira vez, estabeleceu e classificou desse modo a diferença metodológica em relação à interpretação da Constituição- sobre como deve ser encarada, metodicamente, a interpretação da Constituição. Segundo Grey, duas são as posições que se contrapõem: o interpretativismo e o não-interpretativismo. $\mathrm{O}$ interpretativismo relaciona-se à postura origininalista que os limites de liberdade de conformação do legislador devem se dar nos limites do texto escrito; ou seja, basta a grafia constitucional para que os limites ao processo político sejam determinados e instaurados. Já as posturas não-interpretativistas postulam uma espécie de política constitucional, aproximando-se das idéias defendidas pelo realismo jurídico ${ }^{19}$.

Ora, por certo que, ao defender a possibilidade e a necessidade de respostas corretas em direito (ou, na formula que proponho: respostas adequadas constitucionalmente), não é possível ter-me como um interpretativista (originalista). Isso por um motivo simples: quando afirmo tal tese, tenho por pressuposto que a dicotomia interpretacionismo/não-interpretacionismo está - de há muito- superada e os problemas daí decorrentes já tenham sido sanados. Isto porque, quando em Law's Empire Dworkin enfrenta o aguilhão semântico e o problema do pragmatismo, há uma inevitável superação das teses clássicas sobre a interpretação da Constituição americana. Ou seja, o problema da resposta correta não se resume à identificação da sentença judicial com o texto da lei ou da Constituição. Se pensássemos assim, estaríamos ainda presos aos dilemas das posturas semânticas. Quando se fala em resposta correta há uma série de acontecimentos que atravessam o direito que ultrapassam o mero problema da "literalidade do texto".

Daí a confusão operada por Appio: para ele, quando assevero que os limites semânticos do texto devem ser respeitados, como no caso do problema envolvendo o casamento de pessoas do mesmo sexo, conclui de minha abordagem um inexplicável viés de contenção judicial em benefício de uma

p. 207. As obras em referencia som: STRECK, Lenio Luiz, Hermenêutica jurídica e (m) crise (10a edição, Porto Alegre, Livraria do Advogado, 2011); El Mismo, Jurisdição constitucional e hermenêutica (2a edição, Rio de Janeiro, Forense, 2004); El Mismo, Verdade e consenso (4a edição, São Paulo, Saraiva, 2011).

${ }^{19}$ Grey, Thomas, Do We Have an Unwritten Constitution? in Stanford Law Review, 27 (1975), p. 703. 
estrita exegese, de acordo com a literalidade da norma. Ainda no âmbito da série de equívocos e confusões feitas pelo autor no decorrer do texto, vejase a equivocada afirmação no sentido de que a hermenêutica filosófica "não aponta um caminho a ser seguido, pois apenas recomenda que o intérprete deve deixar a interpretação fluir naturalmente", como se eu estivesse a propor uma modalidade de "laissez faire" hermenêutico. É preciso insistir: a hermenêutica por mim trabalhada é antirelativista e antidiscricionária, o que significa dizer que o sentido não está à disposição do intérprete (o que é diferente de dizer que há uma "exegese de estrita literalidade").

Na verdade, o "drama" da discricionariedade que venho criticando de há muito é que esta transforma os juízes em legisladores. E mais do que transformar os juízes em legisladores, o "poder discricionário" propicia a "criação" do próprio objeto de "conhecimento", típica problemática que remete a questão ao solipsismo característico da filosofia da consciência no seu mais exacerbado grau. Ou seja, concebe-se a razão humana como "fonte iluminadora" do significado de tudo o que pode ser enunciado sobre a realidade. Nesse paradigma, as coisas são reduzidas aos nossos conceitos e às nossas concepções de mundo, ficando à dis-posição de um protagonista (no caso, o juiz, enfim, o Poder Judiciário). E isso acarreta conseqüências graves no Estado Democrático de Direito.

Eis a complexidade: historicamente, os juízes eram acusados de ser a boca da lei. Essa crítica decorria da cisão entre questão de fato e questão de direito, isto é, a separação entre faticidade e validade (problemática que atravessa os séculos). As diversas teorias críticas sempre aponta(ra)m para a necessidade de rompimento com esse imaginário exegético. Ocorre que, ao mesmo tempo, a crítica do direito, em sua grande maioria, sempre admitiu -e cada vez admite mais- um alto grau de discricionariedade nos casos difíceis, nas incertezas designativas, enfim, na zona de "penumbra" das leis. Tudo isso tem conseqüências sérias para o direito. Seríssimas.

\section{Elementos Conclusivos}

Quando questiono os limites da interpretação, a ponto de alçar a necessidade desse controle à categoria de princípio basilar da hermenêutica jurídica está obviamente implícita a rejeição da negligência do positivismo "legalista" para com o papel do juiz, assim como também a "descoberta" das diversas correntes realistas e pragmatistas que se coloca(ram) como antítese ao exegetismo das primeiras. Ou seja, a questão que está em jogo ultrapassa de longe essa antiga contraposição de posturas, mormente porque, no entremeio destas, surgiram várias teses, as quais, sob pretexto da superação de um positivismo fundado no sistema de regras, construíram um modelo interpretativo 
calcado em procedimentos, cuja função é(ra) descobrir os valores presentes (implícita ou explicitamente) no novo direito, agora "eivado de princípios e com textura aberta".

Já as posturas subjetivistas, especialmente, redundaram em um fortalecimento do protagonismo judicial, fragilizando sobremodo o papel da doutrina. Em terrae Brasilis essa problemática é facilmente notada no impressionante crescimento de uma cultura jurídica cuja função é reproduzir as decisões tribunalícias. É o império dos enunciados assertóricos que se sobrepõe à reflexão doutrinária. Assim, os reflexos de uma aposta no protagonismo judicial não demorariam a serem sentidos: a doutrina se contenta com "migalhas significativas" ou "restos dos sentidos previamente produzidos pelos tribunais". Com isso, a velha jurisprudência dos conceitos acaba chegando ao direito contemporâneo a partir do lugar que era o seu destinatário: as decisões judiciais, ou seja, são elas, agora, que produzem a conceitualização. Com uma agravante: o sacrifício da faticidade; o esquecimento do mundo prático.

De todo modo, o ponto fulcral não está nem no exegetismo, nem no positivismo fático (por todos, basta examinar as teses do realismo jurídico nas suas variadas perspectivas) e tampouco nas teorias que apostam na argumentação jurídica como um passo para além da retórica e como um modo de "corrigir as insuficiências do direito legislado". Na verdade, o problema, em qualquer das teses que procuram resolver a questão de como se interpreta e como se aplica, localiza-se no sujeito da modernidade, isto é, no sujeito "da subjetividade assujeitadora", objeto da ruptura ocorrida no campo da filosofia pelo giro linguístico-ontológico e que não foi recepcionado pelo direito.

Isso significa poder afirmar que qualquer fórmula hermenêutico-interpretativa que continue a apostar no solipsismo estará fadada a depender de um sujeito individualista (ou egoísta, para usar a melhor tradução da palavra em alemão "Selbstsüchtiger"), como que a repristinar o nascedouro do positivismo através do nominalismo. Está-se lidando, pois, com rupturas paradigmáticas e princípios epocais que fundamentam o conhecimento em distintos períodos da história (do eidos platônico ao último princípio fundante da metafísica moderna: a vontade do poder, de Nietzsche).

Em síntese -e quero deixar isso bem claro- para superar o positivismo é preciso superar também aquilo que o sustenta: o primado epistemológico do sujeito (da subjetividade assujeitadora) e o solipsismo teórico da filosofia da consciência (ou de sua vulgata) ${ }^{20}$. Não há como escapar disso. E penso

${ }^{20}$ Permito-me insistir na "questão da filosofia", embora setores importantes do direito desconsiderem o fato de a filosofia ser a condição de possibilidade do próprio 
que apenas com a superação dessas teorias que ainda apostam no esquema sujeito-objeto é que poderemos sair dessa armadilha que é o solipsismo. A hermenêutica se apresenta nesse contexto como um espaço no qual se pode pensar adequadamente uma teoria da decisão judicial, livre que está tanto das amarras desse sujeito onde reside a razão prática como daquelas posturas que buscam substituir esse sujeito por estruturas ou sistemas. Nisso talvez resida a chave de toda a problemática relativa ao enfrentamento do positivismo e de suas condições de possibilidade.

É tarefa contínua, pois, que se continue a mostrar como persistem equívocos nas construções epistêmicas atuais e como tais equívocos se dão em virtude do uso aleatório das posições dos vários autores que compõe o chamado pós-positivismo. Com efeito, isso fica evidente no conceito de princípio. $\mathrm{O}$ caráter normativo dos princípios - que é reivindicado no horizonte das teorias pós-positivistas- não pode ser encarado como um álibi para a discricionariedade, pois, desse modo, estaríamos voltando para o grande problema não resolvido pelo positivismo.

Com isso quero dizer que a tese da abertura (semântica) dos princípios - com que trabalha a teoria da argumentação (e outras teorias sem filiação a matrizes teóricas definidas) - é incompatível com o modelo pós-positivista de teoria do direito. $\mathrm{Na}$ verdade, o positivismo (primitivo ou exegético) sempre nutriu uma espécie de aversão aos princípios. Na medida em que na discussão sobre os princípios sempre nos movemos no território precário da razão prática, o positivismo os trata(va) como uma espécie de reforço que possuía no máximo uma função de integração sistemática. Esse é o significado da doutrina dos princípios ocultos de que fala $\operatorname{Esser}^{21}$ ou seja, uma tentativa de sanar uma possível incompletude sistemática no todo do ordenamento jurídico.

Nessa medida, é preciso ressaltar que só pode ser chamada de pós-positivista uma teoria do direito que tenha, efetivamente, superado o positivismo (nas suas diversas matrizes). Parece óbvio reforçar isso. A superação

direito. De todo modo, faço a seguinte observação: o que se tem visto no plano das práticas jurídicas nem de longe chega a poder ser caracterizada como "filosofia da consciência”. Trata-se de uma vulgata disso. Em meus textos, tenho falado que o solipsismo judicial, o protagonismo e a prática de discricionariedades se enquadram paradigmaticamente no "paradigma epistemológico da filosofia da consciência". Advirto, porém, que é evidente que o modus decidendi não guarda estrita relação com o "sujeito da modernidade" ou até mesmo com o "solipsismo kantiano". Esses são muito mais complexos. Aponto essas "aproximações" para, exatamente, poder fazer uma anamnese dos discursos, até porque não há discurso que esteja “em paradigma nenhum”, por mais sincrético que seja.

${ }^{21}$ EsSER, Josef, Principio y norma en la elaboración jurisprudencial del derecho privado (Barcelona, Bosch, 1961). 
do positivismo implica enfrentamento do problema da discricionariedade judicial ou, também poderíamos falar, no enfrentamento do solipsismo da razão prática ${ }^{22}$. Implica, também, assumir uma tese de descontinuidade com relação ao conceito de princípio. Ou seja, no pós-positivismo os princípios não podem mais serem tratados no sentido dos velhos princípios gerais do direito nem como cláusulas de abertura.

De efetivo, uma teoria pós-positivista necessita superar os três elementos fundantes dos diversos positivismos jurídicos:

Primeiro, porque o positivismo sempre se caracterizou pelas fontes sociais do direito, pela separação entre direito e moral e pela discricionariedade delegada ao juiz nos "hard cases" ou nas incertezas da linguagem em geral.

Segundo, porque, como já demonstrado alhures, há uma correspondência de tais características com os obstáculos opostos pelo positivismo ao novo constitucionalismo (neoconstitucionalismo): a falta de uma nova teoria das fontes, a falta de uma nova teoria da norma e a ausência de uma teoria da interpretação que dê conta da superação do paradigma objetivista aristotélico-tomista e da filosofia da linguagem. Há, assim, um modo de unificar esses características e os obstáculos, uma vez que é possível vislumbrar uma imbricação ou cruzamento entre eles.

A partir disso, a elaboração de uma teoria pós-positivista tem que levar em conta os seguintes elementos:

$1^{\circ}$ Há que se ter presente que o direito do Estado Democrático de Direito supera a noção de "fontes sociais", em face daquilo que podemos chamar de prospectividade, isto é, o direito não vem a reboque dos "fatos sociais" e, sim, aponta para a reconstrução da sociedade. Isso é facilmente detectável nos textos constitucionais, como em terrae brasilis, onde a Constituição estabelece que o Brasil é uma República que visa a erradicar a pobreza, etc, além de uma gama de preceitos que estabelecem as possibilidades (e determinações) do resgate das promessas incumpridas da modernidade.

$2^{\circ}$ Essa problemática tem relação direta com a construção de uma nova teoria das fontes, uma vez que a Constituição será o locus da construção do direito dessa nova fase do Estado (Democrático de Direito); consequentemente, não mais há que se falar em qualquer possibilidade de normas jurídicas

${ }^{22}$ Segundo Campbell, Tom, El sentido del positivismo jurídico, en Doxa. Cuadernos de Filosofía del Derecho, alicante, 25 (Alicante, 2002), p. 303-331, todos os positivistas defendem, em alguma medida, juízos discricionais, ao menos como soluções do tipo $o$ segundo melhor, que podem ser a melhor prática quando o aplicador se depara com normas formalmente más. As regras bastante arbitrárias de interpretação do direito legislado podem ser vistas como mecanismos artificias para limitar tal discrição de uma forma em que se comprometem menos os ideais tais como a certeza e a conclusividade, em que o positivismo jurídico descansa. 
que contrariem a Constituição e que possam continuar válidas; mais do que isso, muda a noção de parametricidade, na medida em que a Constituição pode ser aplicada sem a interpositio legislatoris, fonte de serôdias teorias que relativizavam a validade/eficácia das normas.

$3^{\circ}$ Não pode restar dúvida de que tanto a separação como a dependência/ vinculação entre direito e moral estão ultrapassadas, em face daquilo que se convencionou chamar de institucionalização da moral no direito (esta é uma fundamental contribuição de Habermas para o direito: a co-originariedade entre direito e moral), circunstância que reforça, sobremodo, a autonomia do direito. Isto porque a moral regula o comportamento interno das pessoas, só que esta "regulação" não tem força jurídico-normativa. O que tem força vinculativa, cogente, é o direito, que recebe conteúdos morais (apenas) quando de sua elaboração legislativa ${ }^{23}$. Observemos: é por isso que o Estado

${ }^{23}$ Aqui cabe um esclarecimento, para novamente evitar mal entendidos. A elaboração legislativa não esgota - nem de longe - o problema do conteúdo do direito. Quando concordamos que as questões morais, políticas, etc, façam parte da "tarefa legislativa”, isso não quer dizer que haja, de minha parte -e, por certo, dos adeptos das posições substancialistas- uma viravolta na questão "procedimentalismo-substancialismo". Se as posturas procedimentalistas pretendem esgotar essa discussão a partir da garantia do processo democrático de formação das leis, isso, no entanto, não esgota a discussão da concreta normatividade, locus do sentido hermenêutico do direito. De fato, mais do que apostar na formulação democrática do direito, há que se fazer uma aposta paradigmática, isto é, acreditar na perspectiva pós-positivista do novo constitucionalismo e sua materialidade principiológica. A virtude soberana não se dá simplesmente na formulação legislativa e na "vontade geral”. Fundamentalmente, ela será encontrada na Constituição, que estabeleceu uma ruptura com a discricionariedade política que sempre sustentou o positivismo. E tudo isso está ancorado no contramajoritarismo, que vai além do mero controle da aferição da correção dos procedimentos democráticos utilizados na feitura das leis. Também é na Constituição que encontraremos os mecanismos de controle da aferição substancial dos textos legislados e da aplicação destes textos (nunca esqueçamos: o substancialismo não abre mão do procedimentalismo). A igualdade, o devido processo legal, o sentido do republicanismo, a perspectiva de Estado Social, a obrigação de concretização dos direitos fundamentais-sociais, para citar apenas estes componentes paradigmáticos, são obrigações principiológicas de raiz, que vinculam a applicatio. E os componentes a serem utilizados na discussão da aplicação do direito somente poderão exsurgir desse paradigma constitucional. Legislação democraticamente produzida -e válida- significa "sentido filtrado principiologicamente". O combate que aqui se trava -de cariz anti-discricionário- tem a objetivo de preservar esse grau acentuado de autonomia que o direito adquiriu com a fórmula das Constituições compromissórias (e dirigentes). Portanto, não será um posicionamento ad hoc, fruto de apreciações advindas de uma moral individual ou convicções políticas, etc (em síntese, argumentos de política), que "valerá" mais do que esse "produto democrático", o qual -e é desnecessário frisar isso- deverá sempre passar pelo controle paramétricoconstitucional. Como já referido: a hermenêutica não abre mão do sujeito da relação, 
Democrático de Direito não admite discricionariedade (nem) para o legislador, porque ele está vinculado a Constituição (lembremos sempre a ruptura paradigmática que representou o constitucionalismo compromissório e social). O "constituir" da Constituição é a obrigação suprema do direito. É, pois, a virtude soberana (parafraseando Dworkin). A partir da feitura da lei, a decisão judicial passa a ser racionalizada na lei, que quer dizer, "sob o comando da Constituição" e não "sob o comando das injunções pessoais-morais-políticas do juiz ou dos tribunais". Essa questão é de suma importância, na medida em que, ao não mais se admitir a tese da separação (e tampouco da vinculação), não mais se corre o risco de colocar a moral como corretiva do direito. E isso terá conseqüências enormes da discussão "regra-princípio".

$4^{\circ} \mathrm{Na}$ seqüência e em complemento, tem-se que essa cisão entre direito e moral coloca(va) a teoria da norma à reboque de uma tese de continuidade entre os velhos princípios gerais e os (novos) princípios constitucionais. Sustentado no paradigma do Estado Democrático Constitucional, o direito, para não ser solapado pela economia, pela política e pela moral (para ficar apenas nessas três dimensões predatórias da autonomia do direito), adquire uma autonomia que, antes de tudo, funciona como uma blindagem contra as próprias dimensões que o engendra $(\mathrm{ra}) \mathrm{m}$.

$5^{\circ}$ Tudo isso significa assumir que os princípios constitucionais -e a Constituição lato sensu (afinal, qualquer prospecção hermenêutica que se faça- seja a partir de Dworkin, Gadamer ou Habermas -só tem sentido no contexto do paradigma do Estado Democrático de Direito) - ao contrário do que se possa pensar, não remete para uma limitação do direito (e de seu grau de autonomia), e, sim, para o fortalecimento de sua de autonomia.

$6^{\circ}$ Consequentemente, nos casos assim denominados de "difíceis", não é mais possível "delegar" para o juiz a sua resolução. Isto porque não podemos mais aceitar que, em pleno Estado Democrático de Direito, ainda se postule que a luz para determinação do direito in concreto provenha do protagonista

enfim, do sujeito que lida com objetos. O que ela supera é o esquema sujeito-objeto, responsável pelo sujeito solipsista que sustenta as posturas subjetivistas-axiologistas da maioria das teorias do direito mesmo no século XXI. Na hermenêutica há um efetivo controle da interpretação a partir da tradição (da autoridade desta), da obrigação da integridade, da coerência, da igualdade, da isonomia, enfim, da incorporação dos princípios constitucionais que podemos chamar aqui de virtudes soberanas em homenagem à Dworkin. Por isso, os discursos "predadores" do direito são rechaçados por essa "blindagem hermenêutica" que protege o direito produzido democraticamente. E é exatamente por isso que é possível sustentar respostas adequadas a Constituição, portanto, apostar em uma teoria da decisão e não apenas em uma teoria da legislação. Múltiplas respostas dizem respeito ao relativismo, e, estas, estão umbilicalmente relacionadas com o positivismo. 
da sentença ${ }^{24}$. Isso significa que, para além da cisão estrutural entre casos simples e casos difíceis, não pode haver decisão judicial que não seja fundamentada e justificada em um todo coerente de princípios que repercutam a história institucional do direito. Desse modo, tem-se por superada a discricionariedade a partir do dever fundamental de resposta correta que recai sobre o juiz no contexto do paradigma do Estado Democrático de Direito.

\section{BiBLIOGRAFÍA}

Appio, Eduardo, Direitos das minorias (São Paulo, Revista dos Tribunais, 2009).

Campbell, Tom, Elsentido del positivismo jurídico, en Doxa. Cuadernos de Filosofía del Derecho, alicante, 25 (Alicante, 2002).

Canotilho, J. J. Gomes, Direito constitucional e teoria da Constituição (7a edição, Coimbra, Almedina, 2003).

Dworkin, Ronald, Direito de liberdade. Leitura moral da Constituição americana (São Paulo, Martins Fontes, 2006).

Dworkin, Ronald, Levando os direitos a Sério (tradução de Nelson Boeira, São Paulo, Martins Fontes, 2002).

ESSER, Josef, Principio y norma en la elaboración jurisprudencial del derecho privado (Barcelona, Bosch, 1961).

Gadamer, Hans-Georg, Verdade e método. Traços fundamentais de uma hermenêutica filosófica, (Tradução de Flávio Paulo Meurer, 3a edição, Petrópolis, Vozes, 1999).

Grey, Thomas C, Do We Have un Unwritten Constitution?" in Stanford Law Review, 27 (1975).

HART, Herbert, $O$ conceito de Direito (tradução de A. Ribeiro Mendes. $3^{a}$ edição, Lisboa, Calouste Gulbenkian, 1996).

Kelsen, Hans, Teoria pura do Direito (tradução de João Baptista Machado, São Paulo, Martins Fontes, 1985).

${ }^{24}$ Do mesmo modo, a ideia de imparcialidade pura do juiz ou o uso de estratégias argumentativas para isentar a responsabilidade do julgador no momento decisório podem levar à introdução de argumentos de política na decisão jurídica. Nesse sentido são precisas as afirmações de Dworkin, Ronald, Direito de liberdade. Leitura moral da Constituição americana (São Paulo, Martins Fontes, 2006), p. 57: "A política constitucional tem sido atrapalhada e corrompida pela ideia falsa de que os juízes (se não fossem tão sedentos de poder) poderiam usar estratégias de interpretação constitucional politicamente neutras. Os juízes que fazem eco a essa ideia falsa procuram ocultar até de si próprios a inevitável influência de suas próprias convicções, e o que resulta daí é uma suntuosa mendacidade. Os motives reais das decisões ficam ocultos tanto de uma legítima inspeção pública quanto de um utilíssimo debate público. Já a leitura moral prega uma coisa diferente. Ela explica porque a fidelidade à Constituição e ao direito exige que os juízes façam juízos atuais de moralidade política e encoraja assim a franca demonstração das verdadeiras bases destes juízos, na esperança de que os juízes elaborem argumentos mais sinceros, fundados em princípios, que permitam ao público participar da discussão". 
MÁrtires Coelho, Inocêncio, Interpretação constitucional (Porto Alegre, Fabris, 1992).

Sarmento, Daniel, Interpretação constitucional, pré-compreensão e capacidades institucionais do intérprete, in Pereira de Souza Neto, Claudio - Sarmento - Binembojn, Gustavo (Org.), Vinte Anos da Constituição Federal de 1988 (Rio de Janeiro, Lumen Juris, 2009).

Stein, Ernildo, Diferença e Metafísica: Ensaio sobre a desconstrução (Porto Alegre, Edipucrs, 2000).

Stein, Ernildo, Uma breve introdução à Filosofia (2a edição, Ijuí, Unijuí, 2005).

STRECK, Lenio Luiz, Hermenêutica jurídica e $(m)$ crise $\left(10^{a}\right.$ edição, Porto Alegre, Livraria do Advogado, 2011).

STRECK, Lenio Luiz, Jurisdição constitucional e hermenêutica ( $2^{\mathrm{a}}$ edição, Rio de Janeiro, Forense, 2004).

STreck, Lenio Luiz, Verdade e consenso (4a edição, São Paulo, Saraiva, 2011). 